\title{
Microbially Induced Carbonate Precipitation Using Microorganisms Enriched from Calcareous Materials in Marine Environments and Their Metabolites
}

\author{
Yumi Kim and Yul Roh *(D) \\ Department of Earth and Environmental Sciences, Chonnam National University, Gwangju 61186, Korea; \\ yumddalki@hotmail.com \\ * Correspondence: rohy@jnu.ac.kr; Tel.: +82-62-530-3458
}

Received: 12 August 2019; Accepted: 18 November 2019; Published: 21 November 2019

\begin{abstract}
Microbially induced Ca-carbonate precipitation (MICP) in general, refers to a process in which the urease secreted by microbes hydrolyzes urea to ammonium and carbon dioxide. The main objectives of this study were to identify the environmental factors (e.g., microbial growth, cell/metabolite presences, and calcium sources) that control Ca-carbonate formation and to investigate the mineralogical characteristics of the Ca-carbonate precipitated using ureolytic microorganisms cultured in marine environments. The two types of carbonate-forming microorganisms (CFMs), mixed cultures hydrolyzing urea, were enriched from calcareous materials in marine environments. The experiments using a CFM, Sporosarcina pasteurii, was also used for comparison. All the microbes were cultured aerobically in D-1 growth media that included urea. To investigate the effect of microbial growth states on Ca-carbonate precipitation, Ca-acetate was injected into the media before (i.e., lag phase) and after (i.e., stationary phase) microbial growth, and into the soluble microbial products (SMP) solution, respectively. XRD, FT-IR, and SEM-EDS analyses were used for mineralogical characterization of the precipitated Ca-carbonates. Results indicated that the Ca-carbonates, vaterite and/or calcite, precipitated under all the experimental conditions. The fastest precipitation of Ca-carbonates occurred in the SMP solution and formed calcite (size $=5-15 \mu \mathrm{m}$ ). When the concentrations of added Ca-acetate were varied from 0 to $0.5 \mathrm{M}$, the highest amounts of calcite, $22.8 \mathrm{~g} / \mathrm{L}$, were produced when $0.3 \mathrm{M} \mathrm{Ca}$-acetate was injected. Therefore, the environmental factors (e.g., microbial growth, cell/metabolite presences, and calcium sources) could have an effect the rate of formation of Ca-carbonate and the types of carbonate minerals formed. Moreover, the use of cell-free SMP solution is expected to be applicable to Ca-carbonate precipitation in an environment where microbial growth is unfavorable.
\end{abstract}

Keywords: biomineralization; carbonate; calcite; ureolysis; MICP

\section{Introduction}

Microbially induced carbonate precipitation (MICP) is a ubiquitous process that plays the important roles of metal co-precipitation and cementation in natural systems, such as caves, sediments, and open-water areas [1,2]. Various carbonate forming microorganisms (CFMs), including Bacillus and Pseudomonas, are known to induce carbonate precipitation by altering a solution's chemistry through different metabolic pathways, such as photosynthesis [3], ureolysis [4], denitrification [5], ammonification [6], and sulfate reduction [7]. The most reported calcification processes in the natural environment are achieved through photosynthesis and ureolysis [2]. In ureolysis, microbes hydrolyze 
urea to ammonium and carbon dioxide. This causes an increase in the surrounding $\mathrm{pH}$ which promotes the precipitation of Ca-carbonate $\left(\mathrm{CaCO}_{3}\right)$ in calcium-rich environments [8] (Equation (1)):

$$
\left(\mathrm{NH}_{2}\right)_{2} \mathrm{CO}+2 \mathrm{H}_{2} \mathrm{O}+\mathrm{Ca}^{2+} \rightarrow 2 \mathrm{NH}_{4}{ }^{+}+\mathrm{CaCO}_{3}
$$

In general, the precipitation of Ca-carbonate is a rather straightforward chemical process which is governed by four parameters: (1) the calcium concentration, (2) the carbonate concentration, (3) the $\mathrm{pH}$, and (4) the availability of nucleation sites $[9,10]$. Each of these factors greatly affect either the urease activity of bacteria or the formation of crystals. Recently, many studies have reported that microbial metabolites are associated with Ca-carbonate formation. For instance, Ercole et al. [11] reported that extracellular polymeric materials, such as exopolysaccharides (EPS) and capsular polysaccharides (CPS) isolated from calcifying bacteria, were involved in Ca-carbonate precipitation by serving as nucleation sites and playing an active role in crystal formation. Li et al. [12] also suggested that the extracellular carbonic anhydrase (CA) produced by bacteria may promote calcite precipitation as an activator. However, yet much remains to be revealed about the mechanisms underpinning the ways in which acidic organic molecules affect biomineral composition, microstructure, morphology, and size [13]. Cao et al. [14] showed that mycelia, soluble microbial products (SMP), and their combinations could have effects on mineral morphology and polymorphs. In addition, they showed that the effects of mycelium pellets as a molecular template almost gained an advantage over SMP both in crystal nucleation and growth, having nothing to do with biological activity [14]. In order to understand and to apply the MICP effectively, it is necessary to evaluate both microbial activity and microbial metabolites on Ca-carbonate formation, but there are few related studies on carbonate formation using ureolytic microorganisms. Therefore, the objectives of this study were to identify environmental factors (e.g., microbial growth, cell/metabolite presences, and calcium sources) that control Ca-carbonate formation and to investigate the mineralogical characteristics of the Ca-carbonate precipitated using ureolytic microorganisms cultured in marine environments.

\section{Materials and Methods}

\subsection{Carbonate Forming Microorganisms (CFMs)}

Two types of carbonate-forming microorganisms (CFMs), WD-1 and GP-1, were enriched with calcareous materials in the marine environments of South Korea. Both are mixed cultures that hydrolyze urea. WD-1, mainly consisting of Proteus mirabilis, was enriched from the rhodoliths composed of Mg-rich calcite on the coast in Wudo, Jeju Island [15]. GP-1, on the other hand, was enriched from the calcareous tubes, which was formed by Serpula vermicularis and attached to a rock, on the Geokpo beach in Buan-gun, Jeollabuk province. In addition, Sporosarcina pasteurii KCTC 3558, which is known to induce Ca-carbonate precipitation by ureolysis [16], was used for comparison with the indigenous microorganisms. The strain of S. pasteurii KCTC 3558 was procured from Korean Collection for Type Culture (KCTC, Daejeon, Korea). The medium modified from D-1 [15,16] for CFMs growth and carbonate precipitation contained the following ingredients: $10 \mathrm{~g} / \mathrm{L}$ yeast extract, $5 \mathrm{~g} / \mathrm{L}$ proteose peptone, $1 \mathrm{~g} / \mathrm{L}$ glucose, $35 \mathrm{~g} / \mathrm{L} \mathrm{NaCl}$, and $20 \mathrm{~g} / \mathrm{L}$ Urea. The medium was autoclaved at $121^{\circ} \mathrm{C}$ and $1.2 \mathrm{kgf} / \mathrm{cm}^{2}$ for $20 \mathrm{~min}$. The medium's $\mathrm{pH}$ was about 8.5. The CFMs were cultivated in the medium under aerobic conditions at $25^{\circ} \mathrm{C}$ for 7 days.

\subsection{Ca-Carbonate Precipitation Induced by CFMs}

\subsubsection{The Effect of Microbial Growth on Ca-Carbonate Precipitation}

All the microbes were cultured aerobically in D-1 growth media that included urea. To investigate the effect of microbial growth states on Ca-carbonate precipitation, calcium ion (Ca-acetate, $\left(\mathrm{Ca}\left(\mathrm{CH}_{3} \mathrm{CO}_{2}\right)_{2} \cdot \mathrm{H}_{2} \mathrm{O}\right.$, MW: 176.18) was added into the media before (i.e., lag phase) and after (i.e., stationary phase) microbial growth, and into the cell-free SMP solution. Ca-acetate solution was used in 
the experiment after making a stock solution $(1 \mathrm{M})$ sterilized through autoclaving. Microorganisms $(1 \%)$ were injected into a $50 \mathrm{~mL}$ conical tube containing $30 \mathrm{~mL}$ of the growth media to form a lag phase $\left(\mathrm{OD}_{600}\right.$ $=0.1$. This is an initial stage of microorganism growth. A $30 \mathrm{mM}$ solution of Ca-acetate was added as the Ca ion source. The reaction was aerobically incubated for one week in the shaking incubator at $200 \mathrm{rpm}$ and $30^{\circ} \mathrm{C}$. The Ca-carbonate precipitation induced by microbial growth was then observed. The stationary phase $\left(\mathrm{OD}_{600}=1.0\right.$ containing approx. $10^{7}$ cells $\left./ \mathrm{mL}\right)$, which is a microorganism grew to reach maximum biomass, was prepared by aerobic incubation of the microorganisms in the lag phase for a week. This culture contained the highest number of microbial cells and a large amount of substances secreted during bacterial metabolism. An alkaline environment with a $\mathrm{pH} 9$ resulted from ureolytic microorganisms cultured in marine environments. To confirm the effect of the metabolites produced by microbial growth on Ca-carbonate precipitation, the cells were removed from the culture by centrifugation at $2000 \mathrm{rpm}$ for $5 \mathrm{~min}$. And then, the supernatant was filtered with a $0.2 \mu \mathrm{m}$ membrane filter to obtain the soluble microbial products (SMP) such as polysaccharides, proteins, or amino acids [14]. The filtered supernatant was called the SMP solution. To induce Ca-carbonate precipitation, $30 \mathrm{mM}$ Ca-acetate was injected into each of the stationary phase cultures $\left(\mathrm{OD}_{600}=1.0\right)$ and the SMP solution, respectively. All the samples in the conical tubes were then shaken at $200 \mathrm{rpm}$ to ensure complete mixing at $30^{\circ} \mathrm{C}$ for a week.

\subsubsection{The Effect of Ca-Lactate as a Different Ca-Source}

To investigate the effect of a different calcium source on the precipitation of $\mathrm{Ca}$-carbonate, Ca-lactate $\left.\left(\mathrm{CH}_{3} \mathrm{CH}(\mathrm{OH}) \mathrm{COO}\right)_{2} \mathrm{Ca} \cdot x \mathrm{H}_{2} \mathrm{O} ; \mathrm{MW}: 218.22\right)$ was added into the media prior to microbial growth for comparison with Ca-acetate. Ca-lactate solution was used in the experiment after making a stock solution $(1 \mathrm{M})$ sterilized through autoclave. Microorganisms $(1 \%)$ were then injected into a $50 \mathrm{~mL}$ conical tube containing $30 \mathrm{~mL}$ of the growth media and Ca-lactate of $30 \mathrm{mM}$ was added as Ca ion. The reaction was aerobically incubated for one week in the shaking incubator at $200 \mathrm{rpm}$ and $30^{\circ} \mathrm{C}$ to precipitate Ca-carbonate by microbial growth and metabolism.

\subsubsection{Factors for Maximum Ca-Carbonate Precipitation}

The effects of Ca ion type, Ca ion concentration, and urea presence on the amounts of Ca-carbonate precipitated were investigated. WD-1's SMP solution was used for the experiment because of its excellent Ca-carbonate precipitation ability in the previous experiment. WD-1's SMP solution was obtained from the WD-1 culture by centrifugation and filtration as initially described. First, Ca-acetate and Ca-lactate were added at concentrations of 50 and $100 \mathrm{mM}$, respectively, into $10 \mathrm{~mL}$ of the SMP with or without urea. After $24 \mathrm{~h}$, the precipitate was dried in an electric oven at $60^{\circ} \mathrm{C}$ and the amount of precipitation was measured using an analytical balance. In order to confirm the maximum Ca-carbonate precipitation amounts when using the SMP solution, the concentrations of Ca-acetate were varied from 0 to $0.5 \mathrm{M}$ in the same experiment. All experiments were performed in triplicate.

\subsection{Analytical Methods}

Mineralogical characteristics of the Ca-carbonate precipitated by microbial processes and microbial secretion materials were examined by using X-ray diffraction (XRD) and field emission scanning electron microscopy (FE-SEM) with energy dispersive X-ray (EDS) analyses. To collect the precipitates for XRD and SEM analyses, the suspension was centrifuged with $3000 \mathrm{rpm}$ for $5 \mathrm{~min}$, and then the precipitates were obtained via separation from supernatant parts. The precipitates in the conical tube were washed with distilled water twice, and then dried in an electric oven at $60^{\circ} \mathrm{C}$ to obtain the Ca-carbonate in the solid phase. The XRD analysis was performed by using an Empyrean (Panalytical, Almelo, the Netherlands) equipped with $\mathrm{Cu} K \alpha$ radiation $(40 \mathrm{kV}, 30 \mathrm{~mA})$ at a scan speed of $5 \mathrm{\theta} / \mathrm{min}$. The FE-SEM analysis was conducted on a S-4700 (Hitachi, Tokyo, Japan) at an accelerating voltage of 15-20 kV with EDS (Phillips, Eindhoven, the Netherlands) to determine the morphology and elemental composition of the Ca-carbonates. Fourier transform infrared spectroscopy (FT-IR) is another useful 
tool for identification of $\mathrm{CaCO}_{3}$ polymorphs [14]. FT-IR spectra was obtained by using a VERTEX 70 (Bruker, Billerica, MA, USA) at room temperature with $\mathrm{KBr}$ discs in the $600-1200 \mathrm{~cm}^{-1}$ region.

\section{Results}

\subsection{The Effect of Microbial Growth on Ca-Carbonate Precipitation}

The results indicated that $\mathrm{Ca}$-carbonate precipitates were formed under all experimental conditions except for the control without microorganisms. However, it was observed that differences of the growth of microorganisms in the medium affected the rate of Ca-carbonate production. For instance, when $\mathrm{Ca}$ ion was injected into the lag phase $\left(\mathrm{OD}_{600}=0.1\right)$ medium before the microbial growth, Ca-carbonate began to form after $48 \mathrm{~h}$ and gradually increasingly precipitated as microorganisms grew. In the stationary phase $\left(\mathrm{OD}_{600}=1.0\right)$ medium and SMP solution, the white precipitates formed within $30 \mathrm{~min}$ after injecting Ca ion. After 7 days of reaction, the precipitate was characterized by XRD and SEM-EDS analysis. The Ca-carbonates formed during microbial growth was mainly calcite and vaterite (Figure 1a). In WD-1, calcite with strong peak intensity was predominant and vaterite with low peak intensity was observed. On the other hand, the precipitates formed relatively slow, and only vaterite was observed using GP-1. Both calcite and vaterite were formed using KCTC 3558 and Gorospe et al. (2013) [17], with similar results to ours. The minerals showed similar peak intensities. As soon as the calcium ion was injected into the stationary phase culture, Ca-carbonate precipitated. In WD-1 and GP-1, only calcite showing strong peak intensity was formed. However, in KCTC 3558 calcite with strong peak intensity and vaterite with low peak intensity were produced together (Figure 1b). In particular, precipitates formed in all types of microbial SMP solutions consisted of calcite only (Figure 1c). Similar to XRD data, FT-IR spectra showed the absorption bands of calcite at 711-713 and $875-876 \mathrm{~cm}^{-1}$, whereas $745-746$ and $1082-1087 \mathrm{~cm}^{-1}$ were characteristic of vaterite (Figure 2). Although the composition of Ca-carbonate formed by the three kinds of microorganisms was different, vaterite was formed in the lag phase and stationary phase cultures in which microbial cells were included, but not was formed in cell-free SMP solution. In the control, without microorganisms, white gel-type precipitates were observed, but no crystalline precipitates were formed that could be analyzed. Although saturated conditions formed with respect to particular mineral phase, a lack of precipitation in abiotic conditions confirmed that active metabolism of bacteria is essential to induce formation of various carbonate precipitates [18].

As a result of SEM analysis, there were obvious differences in the sizes and shapes among different treatments according to FE-SEM. Ca-carbonate precipitated in the liquid culture of the lag phase exhibited an irregular size and shape (Figure 3). The Ca-carbonate formed in WD-1 was a mass of polycrystals. Spherical particles of about $50 \mu \mathrm{m}$ in diameter were observed (Figure 3a). However, the particles formed in GP-1 were agglomerates of particles less than $5 \mu \mathrm{m}$ in diameter (Figure 3d). In the KCTC 3558, aggregates covered with nodule-like crystals on the surface and round-shaped vaterite with a diameter of about $5 \mu \mathrm{m}$ were observed together (Figure $3 \mathrm{~g}$ ). In stationary phase culture, Ca-carbonate was formed within $30 \mathrm{~min}$ by rapid reaction. With respect to WD-1, cubic shaped-calcite 3-10 $\mu \mathrm{m}$ in size was mainly observed (Figure $3 \mathrm{~b}$ ). In the GP-1 culture, calcite was observed, in which the rhombohedral crystals grew to a round shape of about $10 \mu \mathrm{m}$ (Figure 3e). On the other hand, in the KCTC 3558 culture, 5-10 $\mu \mathrm{m}$ spherical vaterite and rhombohedral calcite were observed together (Figure 3h). In the SMP solutions, which are metabolites of three microorganisms, only calcite was formed but the morphologies of the particles were different. In WD-1's SMP solution, cubic calcite particles 5-10 $\mu \mathrm{m}$ in size were formed (Figure 3c). In GP-1's SMP solution, the calcite particles were $15-20 \mu \mathrm{m}$ in size and had peanut morphologies (Figure 3f). In the solution of KCTC 3558, spherical or peanut shaped calcite deposits with rough surfaces were formed (Figure 3i). Similarly, a previous study reported that biogenic carbonate minerals have a rough surface in the presence of aggregates of nanometer-sized building blocks [19]. The morphology and polymorphism of biominerals were suggestive that mineralization mediated by microbes was strain-specific and associated with various 
biomacromolecular templates [14]. With regard to the rapid precipitation of calcite in the SMP solution, the presence of soluble microbial products (SMP) would have created a local environment which may have favored the chemical reaction with $\mathrm{Ca}^{2+}$, and gradually reached carbonate saturation $[20,21]$. In addition, the alkaline environments and high bicarbonate concentrations formed by the microbial urea decomposition also provided favorable conditions for stable and rapid formation of calcite in the stationary phase cultures and SMP solutions [22]. Therefore, the microbial growth and the presence of soluble microbial products affected the Ca-carbonate formation rate and types of carbonate minerals.

(a)

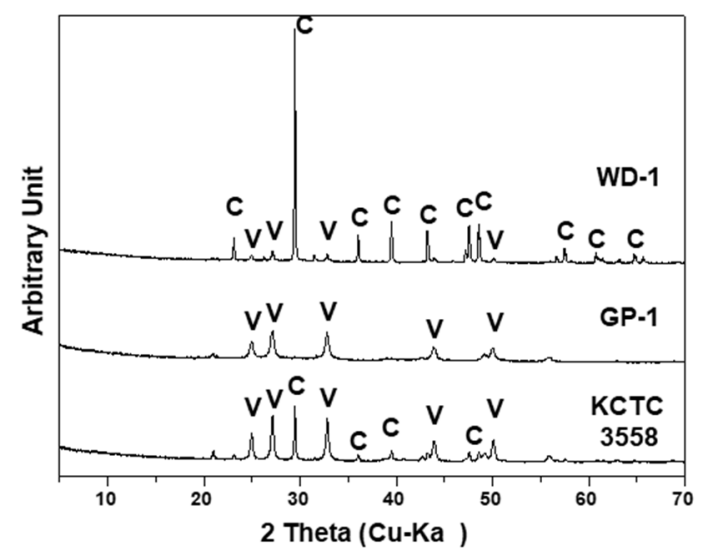

(b)

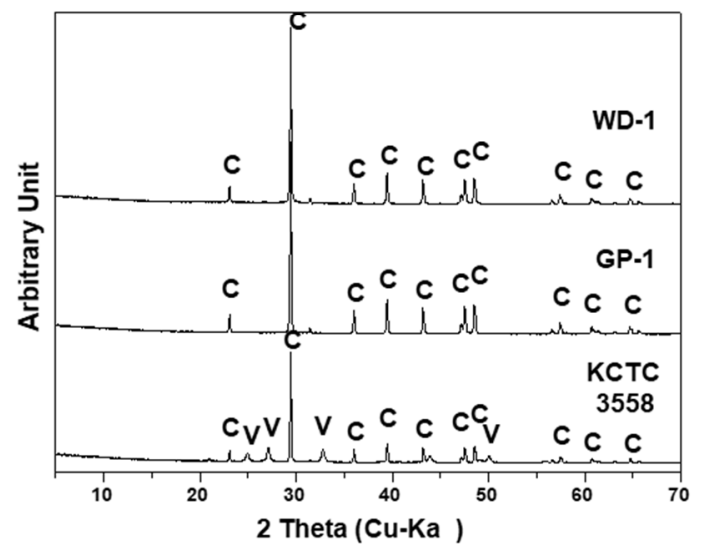

(c)

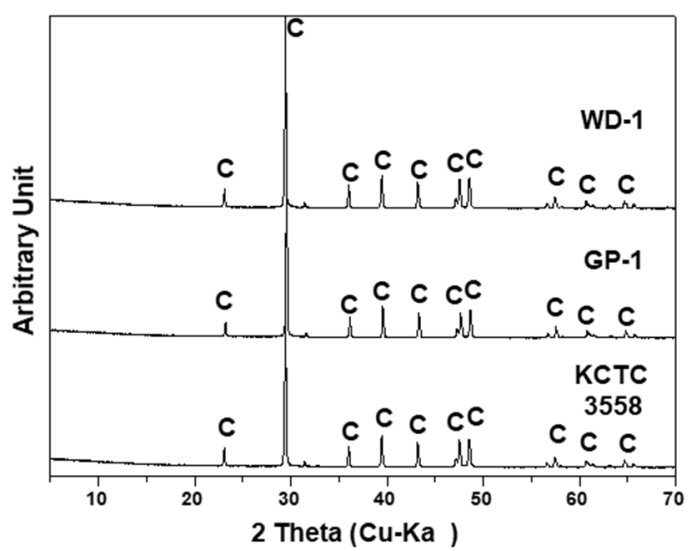

C: calcite $\left(\beta-\mathrm{CaCO}_{3}\right) \quad \mathrm{V}$ : vaterite $\left(\mu-\mathrm{CaCO}_{3}\right)$

Figure 1. XRD patterns showing Ca-carbonate precipitation in different microbial growth states at (a) lag phase or (b) stationary phase, and (c) the SMP solution without cells. 

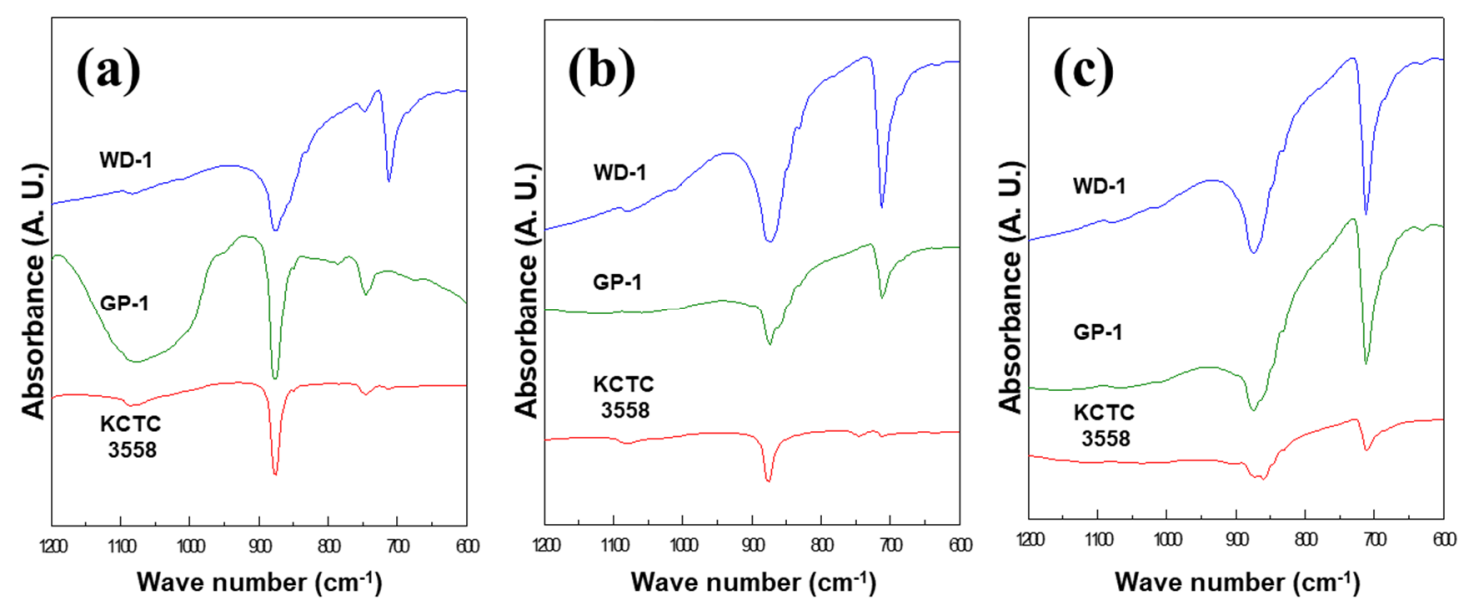

Figure 2. FT-IR spectra showing Ca-carbonate precipitation in different microbial growth states: (a) lag phase or (b) stationary phase and (c) the SMP solution without cells.

\section{Microbial growth in liquid culture}

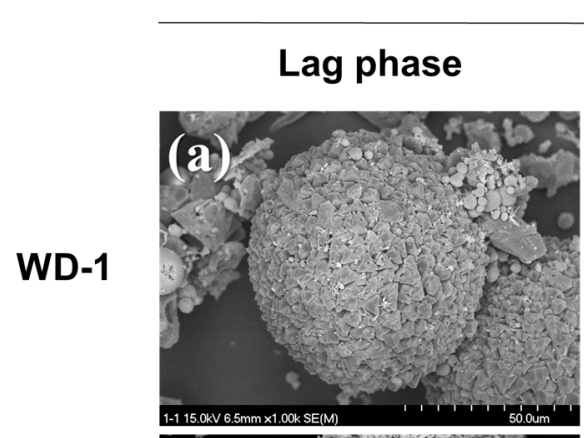

WD-1

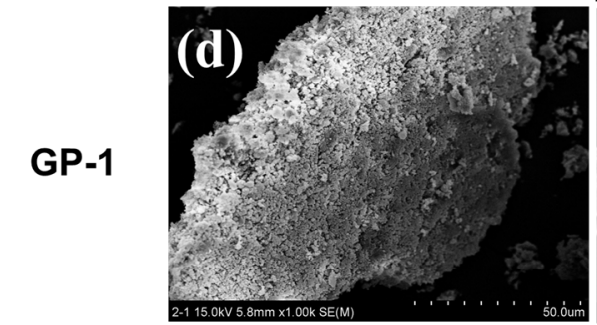

KCTC

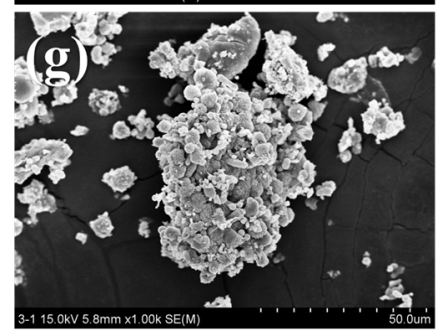

\section{SMP solution}

\section{Stationary phase}
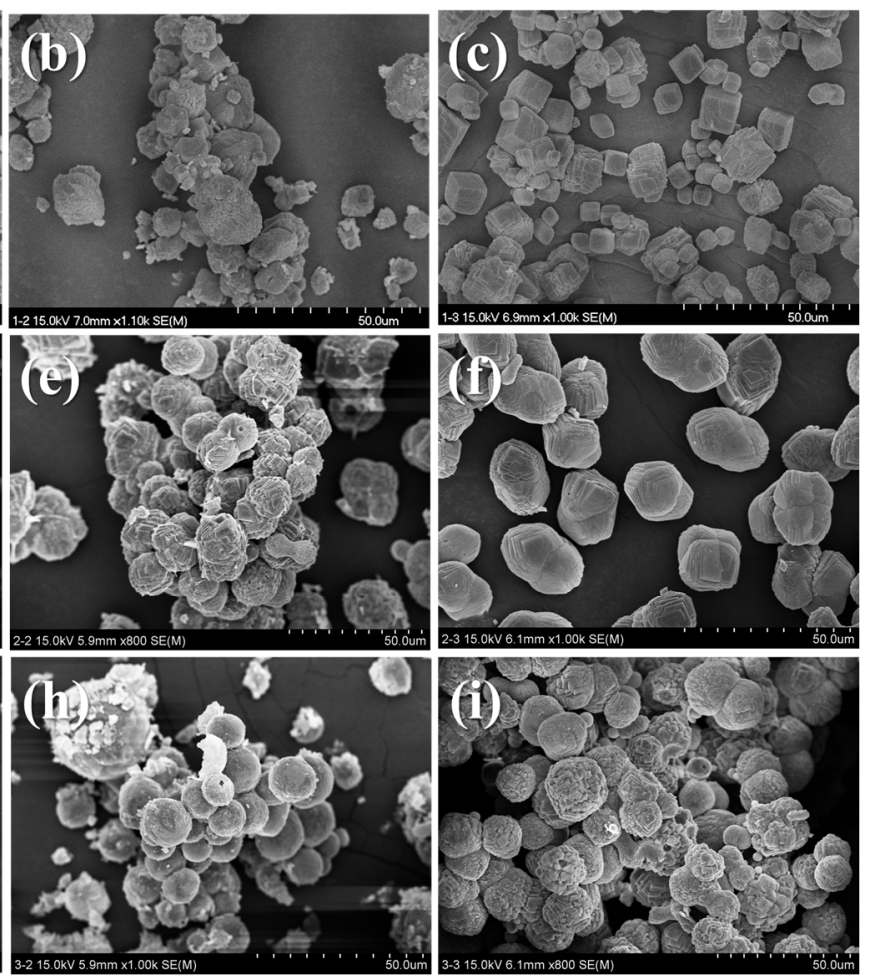

Figure 3. SEM images of Ca-carbonates formed by microorganisms and/or microbial metabolites using Ca-acetate: (a-c) WD-1, (d-f) GP-1, and (g-i) KCTC 3558.

\subsection{The Effect of Ca-Lactate as a Different Ca-Source}

The effect of Ca-lactate instead of Ca-acetate on Ca-carbonate precipitation is as shown in Figure 4. As the Ca-carbonate precipitated by microbial growth and metabolism, calcite was formed by WD-1 while calcite and vaterite were formed by KCTC 3558 using Ca-lactate (Figure 4a). However, GP-1 produced less precipitates $(0.57 \mathrm{~g} / \mathrm{L})$ compared to precipitation by WD-1 $(2.35 \mathrm{~g} / \mathrm{L})$ and KCTC $(3.13$ $\mathrm{g} / \mathrm{L})$ using Ca-acetate. And GP-1 did not form crystalline Ca-carbonate minerals using Ca-lactate. 
The calcite formed by WD-1 was observed as an aggregate of cubic and irregular forms (Figure 4b), while the precipitate formed by GP-1 was seen as an aggregate of amorphous particles (Figure 4c). The amorphous precipitates contained $\mathrm{Ca}$ in the EDS analysis, but no Ca-carbonate related peak was showed in the XRD pattern. Some of the low intensity peaks in XRD data were identified as halite $(\mathrm{NaCl})$ remaining in the washing process to recover precipitates (Figure 4c). When KCTC 3558 was used, the aggregate was observed as a spherical body with a diameter of $50 \mu \mathrm{m}$ composed of small cubic calcites, and vaterite with smooth surface was present in a spherical shape with a diameter of about $10 \mu \mathrm{m}$ (Figure 4d). According to a previous study [17], KCTC 3558 resulted in a different shape of Ca-carbonate depending on the calcium salt used. The use of calcium acetate induced a different shape, a lettuce-like or lamellar shape-a type of vaterite, a metastable form of Ca-carbonate. Meanwhile, the use of calcium lactate gave a spherical shape-another form of vaterite [17]. Compared with those results, when Ca-acetate and Ca-lactate were injected into the growth medium of KCTC 3558, the formations of calcite and vaterite were the same as in the previous study, but the morphological characteristics were different. This indicates that even with the same microorganism, differences in medium composition and incubation conditions could affect Ca-carbonate morphology. The EDS data identified $\mathrm{Ca}, \mathrm{C}$, and $\mathrm{O}$ as the major elements of all precipitates formed by microorganisms. Ca-acetate was more effective than Ca-lactate as a Ca-source for the crystalline Ca-carbonate formation through microbial activity of GP-1. In addition, WD-1 and KCTC 3558 were found to influence the morphological characteristics of Ca-carbonate particles formed depending on Ca-ion species.
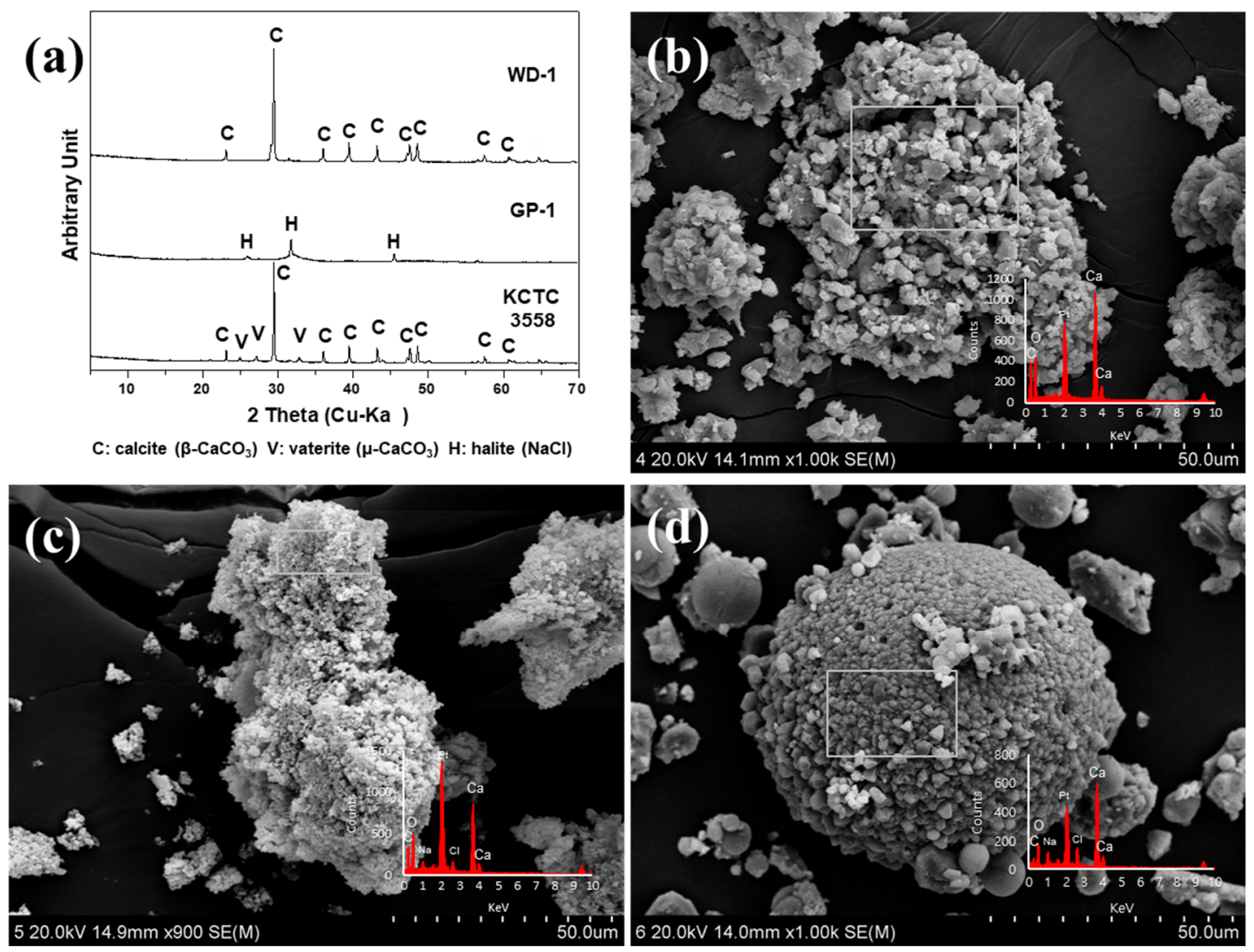

Figure 4. (a) XRD patterns and SEM-EDS images of Ca-carbonates formed by microorganisms using Ca-lactate: (b) WD-1, (c) GP-1, and (d) KCTC 3558.

\subsection{Factors Influencing Maximum Ca-Carbonate Precipitation}

In the experiments to examine effect of microbial growth on Ca-carbonate precipitation, the most rapid precipitation of Ca-carbonates occurred in the cell-free SMP solution which resulted in the formation of calcite $($ size $=5-15 \mu \mathrm{m})$. In order to increase the production rate of Ca-carbonate using 
SMP, it is necessary to investigate the effects of Ca-ion species, Ca-concentration, and urea on the Ca-carbonate production yield and to find the optimum conditions. Figure 5a below compares the amount of Ca-carbonate produced after 0.05 or $0.1 \mathrm{M}$ Ca-acetate and Ca-lactate were added into SMP solution obtained by culturing WD-1 in D-1 medium with or without urea, respectively. In the SMP of the culture medium without urea, Ca-carbonate was formed at about $2-4 \mathrm{~g} / \mathrm{L}$, and the type and concentration of $\mathrm{Ca}$ ion had little effect on Ca-carbonate production. On the other hand, in the SMP of the culture medium containing urea, the amount of Ca-carbonate increased as the concentration of $\mathrm{Ca}$ ion increased (Figure 5a). This indicates that the increase in $\mathrm{pH}$ in the medium through the decomposition of urea played a significant role in Ca-carbonate precipitation. [23]. When $0.1 \mathrm{M}$ of Ca-acetate was used, the maximum yield was about $11.5 \mathrm{~g} / \mathrm{L}$ and the production amount was also proportional to the concentration of $\mathrm{Ca}$ ion. When the concentrations of Ca-acetate added were varied from 0 to $0.5 \mathrm{M}$, the highest amount of calcite, $22.8 \mathrm{~g} / \mathrm{L}$, was produced when $0.3 \mathrm{M}$ Ca-acetate was injected into SMP solution of WD-1 (Figure 5b). This indicates that urea is degraded by microorganisms, which increases the concentration of bicarbonate and the $\mathrm{pH}$ value $(\mathrm{pH} 9)$ in the medium, and that these geochemical changes in the medium provide a favorable environment to lead to the carbonate precipitation of $\mathrm{Ca}$ ions $[8,22,23]$. In general, Ca-carbonate precipitation requires supersaturation with a saturation index $\left(\mathrm{SI}=\left[\mathrm{Ca}^{2+}\right] \times\left[\mathrm{CO}_{3}{ }^{2-}\right] / \mathrm{Ksp}\right)$ higher than 1 . Since the rate of precipitation is affected by the availability of nucleation sites and by the SI, the addition of foreign substances that catalyze the nucleation process, or the increase of the SI of the medium with respect to Ca-carbonate could increase the precipitation rate [24]. Therefore, increasing the concentration of Ca ions affected the SI value, and microbial metabolites in the SMP solution would have contributed to the promotion of Ca-carbonate nucleation. However, this study showed that the maximum amount of Ca-carbonate production was obtained when 0.3 M Ca-acetate was injected. To understand the relationship between Ca-concentration and carbonate mineral production, further studies are required to examine the carbonate mineral precipitation in combination with chemical analyses via the mechanism of microbially-induced carbonate precipitation.

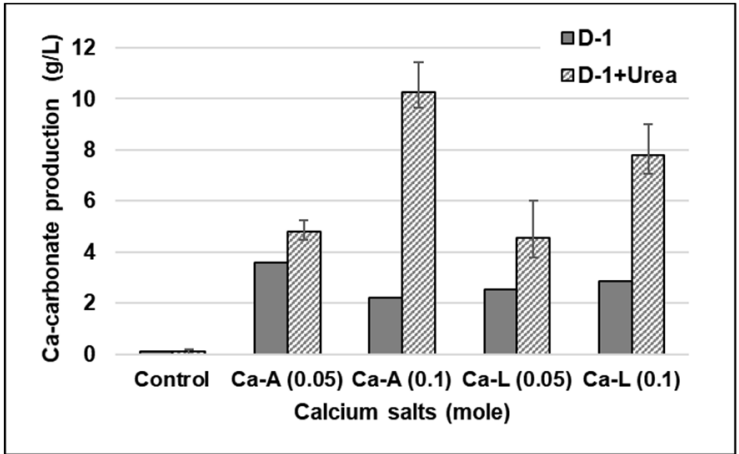

(a)

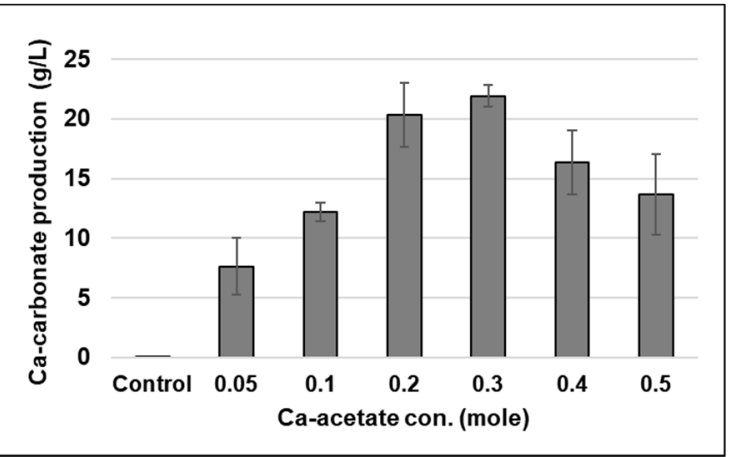

(b)

Figure 5. (a) The effects of Ca-ion species, Ca-concentration, urea, and (b) various concentrations of Ca-acetate on Ca-carbonate yield.

\section{Conclusions}

The two types of carbonate-forming microorganisms (CFMs), WD-1 and GP-1 mixed cultures hydrolyzing urea, were enriched from calcareous materials in marine environments. The experiments using a CFM, Sporosarcina pasteurii, were used for comparison. Results showed that Ca-carbonate was formed during the growth of microorganisms as well as within microbial cultures containing metabolites. When Ca-ions were injected before the microbial growth (i.e., lag phase), Ca-carbonates, mainly calcite and vaterite, were slowly formed. On the other hand, when Ca-ions were added into the microbial grown culture (i.e., stationary phase) or cell-free SMP solution, calcium carbonate precipitated rapidly, and calcite was predominantly formed. This indicated that the formation of Ca-carbonates was not affected by the presence of microbial cells. However, the increase in the 
number of microbial cells and metabolites would have contributed to the promotion of Ca-carbonate precipitation. The most rapid precipitation of Ca-carbonates occurred in the cell-free SMP solution, forming calcite (size $=5-15 \mu \mathrm{m}$ ), and the maximum production was obtained when $0.3 \mathrm{M} \mathrm{Ca}$-acetate was injected. Therefore, the various environmental factors (e.g., microbial growth, cell/metabolite presences, and calcium sources) influenced the formation rate, mineralogical types, and morphological characteristics of the Ca-carbonate precipitated. Moreover, the use of cell-free SMP solution is expected to be applicable to Ca-carbonate precipitation in an environment where microbial growth is unfavorable.

Author Contributions: Y.K. designed the experiments, performed analysis on all samples, interpreted the data, and wrote the manuscript; Y.R. conceived the original idea, provided critical feedback, and acted as the corresponding author.

Funding: This research was supported by National Research Foundation of Korea (NRF-2019R1A2C1010286) and ICT (NRF-2017M1A8A1072024).

Acknowledgments: We are grateful to Moon at KBSI-Gwangju Branch for SEM-EDS, and Jung and Kim at CCRF in Chonnam National University for XRD and FT-IR analyses.

Conflicts of Interest: The authors declare no conflict of interest.

\section{References}

1. Chou, C.-W.; Seagren, E.A.; Aydilek, A.H.; Lai, M. Biocalcification of sand through ureolysis. J. Geotech. Geoenviron. Eng. 2011, 137, 1179-1189. [CrossRef]

2. Zhu, T.; Dittrich, M. Carbonate precipitation through microbial activities in natural environment, and their potential in biotechnology: A review. Front. Bioeng. Biotechnol. 2016, 4, 4. [CrossRef] [PubMed]

3. Gattuso, J.-P.; Allemand, D.; Frankignoulle, M. Photosynthesis and calcification at cellular, organismal and community levels in coral reefs: A review on interactions and control by carbonate chemistry. Am. Zool. 1999, 39, 160-183. [CrossRef]

4. Bibi, S.; Qualha, M.; Ashfaq, M.Y.; Suleiman, M.T.; Zourari, N. Isolation, differentiation and biodiversity of ureolytic bacteria of Qatari soil and their potential in microbially induced calcite precipitation (MICP) for soil stabilization. RSC Adv. 2018, 8, 5854. [CrossRef]

5. Pham, V.P.; Nakano, A.; van der Star, W.R.L.; Heimovaara, T.J.; van Paassen, L.A. Applying MICP by denitrification in soils: A process analysis. Environ. Geotech. 2018, 5, 79-93. [CrossRef]

6. Rodriguez-Navarro, C.; Rodriguez-Gallego, M.; Ben Chekroun, K.; GonzalezMunoz, M.T. Conservation of ornamental stone by Myxococcus xanthus-induced carbonate biomineralization. Appl. Environ. Microbiol. 2003, 69, 2182-2193. [CrossRef]

7. Warthmann, R.; van Lith, Y.; Vasconcelos, C.; McKenzie, J.A.; Karpoff, A.M. Bacterially induced dolomite precipitation in anoxic culture experiments. Geology 2000, 28, 1091-1094. [CrossRef]

8. Phillipsa, A.J.; Troyer, E.; Hiebert, R.; Kirkland, C.; Gerlach, R.; Cunningham, A.B.; Spangler, L.; Kirksey, J.; Rowe, W.; Esposito, R. Enhancing wellbore cement integrity with microbially induced calcite precipitation (MICP): A field scale demonstration. J. Pet. Sci. Eng. 2018, 171, 1141-1148. [CrossRef]

9. Mitchell, A.C.; Dideriksen, K.; Spangler, L.H.; Cunningham, A.B.; Gerlach, R. Microbially enhanced carbon capture and storage by mineral-trapping and solubility-trapping. Environ. Sci Technol. 2010, 44, 5270-5276. [CrossRef]

10. Hammes, F.; Verstraete, W. Key roles of $\mathrm{pH}$ and calcium metabolism in microbial carbonate precipitation. Rev. Environ. Sci. Biotechnol. 2002, 1, 3-7. [CrossRef]

11. Ercole, C.; Bozzelli, P.; Altieri, F.; Cacchio, P.; Gallo, M.D. Ca-carbonate mineralization: Involvement of extracellular polymeric materials isolated from calcifying bacteria. Microsc. Microanal. 2012, 18, 829-839. [CrossRef] [PubMed]

12. Li, W.; Liu, L.P.; Zhou, P.-P.; Cao, L.; Yu, L.-J.; Jiang, S.Y. Calcite precipitation induced by bacteria and bacterially produced carbonic anhydrase. Curr. Sci. 2011, 100, 502-508.

13. Kröger, R. Biomineralization: Ion binding and nucleation. Nat. Mater. 2015, 14, 369-370. [CrossRef] [PubMed] 
14. Cao, C.; Jiang, J.; Sun, H.; Huang, Y.; Tao, F.; Lian, B. Carbonate mineral formation under the influence of limestone-colonizing actinobacteria: Morphology and polymorphism. Front. Microbiol. 2016, 7, 366. [CrossRef]

15. Sanchez-Roman, M.; Vasconcelos, C.; Warthmann, R.; Rivadeneyra, M.; McKenzie, J.A. Microbial dolomite precipitation under aerobic conditions: Results from Brejo do Espinho Lagoon (Brazil) and culture experiments. Int. Assoc. Sedimentol. Spec. Publ. 2009, 41, 167-178.

16. Kang, S.; Roh, Y.M. Biomineralization of Mg-enriched Ca-carbonates by aerobic microorganisms enriched from rhodoliths. J. Nanosci. Nanotechnol. 2017, 17, 2329-2332. [CrossRef]

17. Gorospe, C.M.; Han, S.H.; Kim, S.G.; Park, J.Y.; Kang, C.H.; Jeong, J.H.; So, J.S. Effects of different calcium salts on Ca-carbonate crystal formation by Sporosarcina pasteurii KCTC 3558. Biotechnol. Bioprocess. Eng. 2013, 18, 903-908. [CrossRef]

18. Balci, N.; Demirel, C. Formation of carbonate nanoglobules by a mixed natural culture under hypersaline conditions. Minerals 2016, 6, 122. [CrossRef]

19. Rodriguez-Navarro, C.; Jroundi, F.; Schiro, M.; Ruiz-Agudo, E.; González-Muñoz, M.T. Influence of substrate mineralogy on bacterial mineralization of Ca-carbonate: Implications for stone conservation. Appl. Environ. Microbiol. 2012, 78, 4017-4029. [CrossRef]

20. Tourney, J.; Ngwenya, B.T. Bacterial extracellular polymeric substances (EPS) mediate $\mathrm{CaCO}_{3}$ morphology and polymorphism. Chem. Geol. 2009, 262, 138-146. [CrossRef]

21. Tourney, J.; Ngwenya, B.T. The role of bacterial extracellular polymeric substances in geomicrobiology. Chem. Geol. 2014, 386, 115-132. [CrossRef]

22. Chen, L.; Shen, Y.H.; Xie, A.J.; Huang, B.; Jia, R.; Guo, R.Y.; Tang, W.Z. Bacteria-mediated synthesis of metal carbonate minerals with unusual morphologies and structures. Cryst. Growth Des. 2009, 9, 743-754. [CrossRef]

23. Marvasi, M.; Gallagher, L.K.; Martinez, C.L.; Molina Pagan, C.W.; Rodríguez Santiago, E.R.; Vega, C.G.; Visscher, T.P. Importance of B4 medium in determining organomineralization potential of bacterial environmental isolates. Geomicrobiol. J. 2012, 29, 916-924. [CrossRef]

24. Stumn, W. Chemistry of the Solid-Water Interface: Processes at the Mineral-Water and Particle-Water Interface in Natural Systems; Wiley: New York, NY, USA, 1992; pp. 211-242. 